
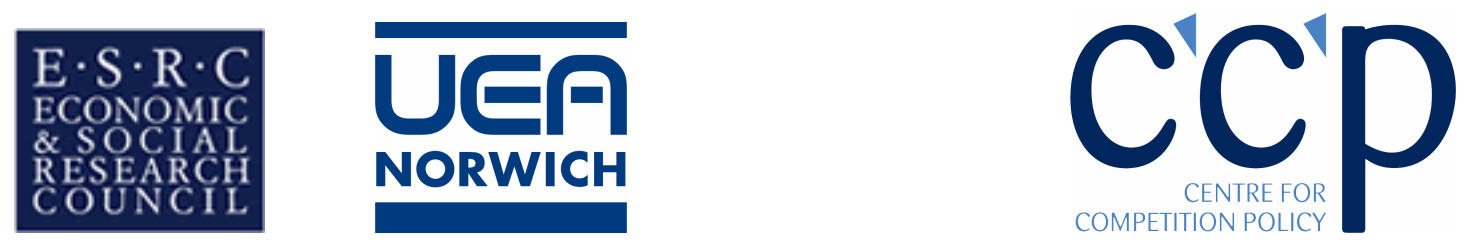

\title{
The Effects of Consumer Protection on Sales Signs, Consumer Search and Competition
}

by

\author{
Chris M. Wilson
}

\section{ESRC Centre for Competition Policy and School of Economics, University of East Anglia}

\section{CCP Working Paper 05-9}

\begin{abstract}
Within a one-shot, duopoly game, we show that firms cannot use false instore price comparisons to deter rational consumers from further beneficial price search in an effort to create market power. However, by introducing a consumer protection authority that monitors price comparisons, we formalise Nelson's (1974) conjecture by showing that 'middle-order' monitoring can actually facilitate the deception of fully rational consumers, to deter them from otherwise optimal search. Despite this effect, we show that no increase in monitoring can ever harm consumers thanks to a second, larger effect that improves consumer information and increases the intensity of price competition.
\end{abstract}

October 2005

JEL Classification: L10; D43; D83

Keywords: Comparative Price Advertising, Deception, Obfuscation, Cheap Talk

Acknowledgements:

I am very grateful for comments made on this and a previous version of the paper, "Price Deception, Market Power and Consumer Policy" (2004), from Steve Davies, Alex Gaudeul, Morten Hviid, and especially Alistair Munro. Thanks also go to the participants at seminars at EARIE (2004) and the University of East Anglia and to Martin Greaves at Trading Standards. The support of the Economic and Social Research Council (UK) is gratefully acknowledged.

Contact details:

christopher.wilson@uea.ac.uk, ESRC Centre for Competition Policy, University of East Anglia, Norwich, NR4 7TJ, UK. www.ccp.uea.ac.uk t: +44 (0) 1603593715

f: + 44(0) 1603591622

ISSN 1745-9648 


\section{Introduction}

While competition policy acts to maintain the quality of consumers' options, consumer protection policy acts to provide the conditions for the effective exercise of consumers' choice over those options (Sylvan 2004). The links between the two policies are clear, and yet, the interface between the two has largely been ignored by economists, despite both the Federal Trade Commission and the UK's Office of Fair Trading recently stressing its importance $^{1}$ (Muris 2002 and Vickers 2003). In this paper, we consider the interface with regard to a specific form of price advertising.

Firms often provide in-store price advertising in the form of price comparisons relative to a past own price ("Was \$9.99, Now \$6.99"), a recommended retail price (“RRP \$9.99, Now \$6.99”), a competitors' price (“Seller X \$9.99, Here \$6.99”) or in some implicit comparison (“Sale \$6.99”, “Low Price \$6.99”, “Only \$6.99”). While previous research has focussed on the impact of these comparisons on (reference-dependent) consumers' willingness to pay (Thaler 1985, Putler 1992), we consider their impact on (rational) consumer search.

Until recently, in some countries such as France and Germany, consumer protection authorities had banned price comparisons, while in countries such as the UK and US, the authorities have always made them subject to monitoring and regulation ${ }^{2}$. This paper aims to understand the mechanisms, and the extent to which, such consumer protection policies affect competition and consumer welfare.

\footnotetext{
${ }^{1}$ Notable exceptions include Beales et al (1981), Vickers (2003) and several strands within the product quality literature concerning the issues of licensing, certification or disclosure (see Carlton and Perloff 1999, for a review).

2 Bans were applied in some European countries until the EU Directive (97/55/EC). harmonised policies in 2000. For the US and UK approach see the FTC's Guide Against Deceptive Pricing at www.ftc.gov/bcp/guides/decptprc.htm and the Code of Practice for Traders on Price Indications at www.dti.gov.uk/ccp/topics1/guide/misleadingprice.pdf. See Barigozzi and Peitz (2004) for a discussion of comparative advertising policies.
} 
To do so, we present a duopoly model where firms select prices (possibly from mixed strategies) and then have the opportunity to make a price comparison to all those consumers who enter their store. In the benchmark case, we show that either banning price comparisons or providing no regulation at all, leaves consumers' search decisions and the market equilibrium unaffected. However, the introduction of a consumer protection policy that monitors and withdraws a fraction of all false comparisons produces two effects. The first effect, the 'competition effect' makes the market more transparent and stimulates fiercer price competition, while the second, adverse effect, the 'deterrence effect', allows firms to anti-competitively use false price comparisons to deter, otherwise optimal consumer search.

The existence of a deterrence effect is notable in several regards. Firstly, it provides a rare characterisation of the deception of rational agents. Indeed, it provides a formalisation of Nelson's (1974) conjecture that 'moderately enforced regulation' may allow firms to deceive consumers by providing a source of credibility for false claims, while not fully dissuading firms from using them. Secondly, it suggests (false) price comparisons can have anticompetitive effects that run counter to the conventional effects of (truthful) price advertising.

To further analyse the effects of consumer protection monitoring, we then go on to show that despite possibly facilitating search deterrence, the procompetitive effects of increased monitoring are so large that no increase in monitoring can ever reduce consumer welfare. With regard to this specific context, we therefore suggest, that it was indeed correct to remove the ban on comparative advertising, and that there exists no conflict of interests between consumer protection and competition authorities.

In section 2, we review some related literature, before we move on to the model in section 3 . The paper's main results are given in section 4 and their 
implications for policy in section 5. Section 6 considers the external validity and robustness of the model. Section 7 concludes.

\section{Some Evidence and Related Literature}

At this point, some readers may instinctively disagree with the notion that firms may deceive consumers with the use of false price comparisons. Before reviewing the relevant literature, we therefore aim to support this notion by i) outlining some successful prosecutions to suggest that firms do indeed use false comparisons, and ii) reviewing the field and experimental evidence in marketing, that suggests false price comparison can have significant effects on consumer behaviour.

Recent prosecutions in the UK include a case in 2003 against a DIY and furniture chain, MFI, for offences including advertising a saving of $50 \%$ on a range of kitchens, when in fact, the actual saving was found to be only $8 \%{ }^{3}$. Similarly, Mark One, a clothing retailer was fined £3000 in 2000 after an investigation found a number of in-store signs suggesting "Many Items Now Up to 75\% Off" when in fact the majority of stocks were discounted by far less than this ${ }^{4}$. In 2001, one of the main supermarket chains, Asda, was prosecuted after making claims that prices were even lower than normal - "Roll back now even lower", when in fact such comparisons had been made to outdated prices $^{5}$, while a clothing store, The Officers Club, was prosecuted in 2005, after the firm offered an insufficient level of products at the advertised discount of "70\% off everything" 6 . In the US, the recent approach to regulation seems to have been more relaxed, but Grewal and Compeau (1992) document several past cases involving department stores making inflated prices comparisons - State of Maryland vs. The Hecht Co. (1985), State of New York vs. Sears, Roebuck and Company (1989), State of New York vs. Sibley, Lindsay and Curr Co. (1990), and Colorado vs. May Department Stores (1990).

\footnotetext{
${ }^{3}$ Consumer Affairs Newsletter, Summer 2003, Leicester Trading Standards

${ }^{4}$ Brent and Harrow Trading Standards Press Release 20 July 2000.

${ }^{5}$ BBC news website, www.bbc.co.uk, September 2001

${ }^{6}$ OFT Press Release May 2005
} 
Numerous experimental and field experiments within the marketing literature have supported the notion that price comparisons can reduce consumers' estimates of the benefits of further search and/or inflate consumers' willingness to pay. Typical evidence, starting with Blair and Landon (1981) randomly assigned subjects to one of several constructed advertisements and asked them for their pre- and post-advertisement intentions, but more persuasive evidence has measured consumers' reactions more realistically. Urbany et al (1988) observed consumers' responses in a laboratory market setting, while Anderson and Simester's (2001) remarkable field experiment involved the careful manipulation of comparisons made in a real-life firms' clothing catalogue. Typically, results suggest that a price comparison itself, regardless of the actual selling price can generate increased demand and reduce search intentions. Indeed, after providing a meta-analysis of the empirical evidence Compeau and Grewal (1998) conclude, "Evidence indicates that comparative price advertising is a powerful advertising tool with a strong opportunity for deception that requires careful management and monitoring"7.

Despite a wealth of empirical research, theoretical treatments of these effects in market contexts are rare. Anderson and Simester (1998), from the perspective of marketing science, consider the optimal number of sales signs a multi-product firm should use across its range of products. Firms compete over fashion products by each offering a range of new and old products each season. Due to the exogenous assumptions of the model, firms find it optimal to lower the price of each product when it becomes old. Instead of potentially using sales signs on all of its new and old products, a firm is shown to optimally limit the number of signs and to prefer placing the signs on genuinely low priced goods. A consumer, who enters a store not knowing whether a given product will be discounted in the future or not, can then

\footnotetext{
${ }^{7}$ Also see the UK's Office of Fair Trading's (2005) research which provides a comprehensive review of their own and other evidence, and Inman et al (1990) and Inman and McAlister (1993) who document similar "promotion signalling" effects.
} 
(probabilistically) trust sales signs to inform their decision of whether to buy immediately or not. Our model differs to theirs in several important respects. Firstly, and most importantly, the focus of our model is on the impact of policy and the implications for competition and welfare, rather than marketing. Secondly, rather than relying on exogenous assumptions to create a special case of dynamic price discrimination, the firms in our model compete within a more general search-theoretic framework so that price dispersion is generated endogenously.

Our model can also be seen to contribute to a wider literature that considers how firms may manipulate consumer search in order to gain market power. Firms can soften market competition by not only trying to deter search, as in the case considered here, but also to distort it. Firms may use, what Ellison and Ellison (2004) refer to as obfuscation strategies, to make search difficult or confusing for consumers. The authors specifically consider the use of add-on prices that make search more costly by distorting search engine results while also discussing how firms may add (meaningless) product dimensions or create complex tariffs, in order to make comparisons between products cognitively difficult ${ }^{8}$. In a different sense, Spiegler (2005) shows the incentive for firms to distort effective search by increasing the variance across product quality dimensions. Ireland (2002) considers a how firms may undermine the effectiveness of consumer search by reducing the chance of a consumer sampling a genuinely different, lower priced firm by filling the market with different named stores that are in fact owned by the same firm.

\section{A Model of Price Comparisons and Consumer Protection}

The model considers a duopoly where both firms sell a single good of known quality. Production costs and capacity constraints are set to zero and so we can denote firm i's profits as $\pi_{i}=p_{i} q_{i} \forall i=\{1,2\}$. Without loss of generality,

\footnotetext{
${ }^{8}$ See Wilson and Waddams Price (2005) for evidence of substantial decision errors made by consumers when switching between suppliers in the UK electricity market that may have been accentuated by the industry's use of complex tariffs.
} 
the number of consumers is normalised to two, $k=\{1,2\}$, and both consumers have unit demand functions with a maximum willingness to pay of $\mathrm{V}>0$. The consumers are located symmetrically such that consumer 1 is 'local' to firm 1 and consumer 2 is 'local' to firm 2. For a consumer k who is local to firm i, it is assumed that the consumer may costlessly visit firm i, but must pay a subsequent search cost $\mathrm{c}>0$ to visit the non-local firm, firm $j \neq i^{9}$. We assume that returning to the local firm after searching the non-local firm is prohibitively expensive - search is without recall (although the model is not dependent upon this assumption, see section 6). The game is comprised of four stages, and is only played once. All agents are risk-neutral and fully rational with orthodox preferences.

In Stage 1, both firms simultaneously select a selling price, $p_{i} \in \mathfrak{R}^{+}$, which remains fixed for the rest of the game. In equilibrium $p_{i}$ will be drawn from a (perhaps degenerate) probability distribution, $F\left(p_{i}\right)$ defined on a (perhaps discontinuous) price support of with a lower and upper bound of $\underline{p}$ and $\bar{p}$.

In Stage 2, only the firms observe the vector of market prices, $P=\left\{p_{1}, p_{2}\right\}$. The firms then have the opportunity to create a costless in-store message that will be viewed by any consumer who visits the firm. A firm's message strategy $\left(m_{i} \mid P\right) \in M$ assigns a message $m_{i}$ from the message space $M=\{$ Sign, NoSign $\}$ for all possible market price contingencies, $P$. We focus only on implicit comparisons by allowing firms to either construct a sales sign or not. Within this simple model, this is not restrictive as we could decompose any instructive communication to a binary signal suggesting whether the consumer could benefit from further search or not. Allowing firms to choose

\footnotetext{
${ }^{9}$ The model uses a slightly unusual search framework based on Shilony (1977). The use of a more standard search model, such as Stahl (1989), would be inconsistent with our model's requirement that consumers make costly, sequential, meaningful search decisions, as consumers would either search without cost (shoppers) or make a costly search only once. Introducing shoppers here would simply further enhance the incentives for firms to compete.
} 
over the exact content of a more explicit price comparison will be discussed in section 6 .

In Stage 3, we introduce a consumer protection authority (CPA). The CPA monitors all firms' messages with an exogenous regulation probability of $w \in[0,1]$, and will withdraw any monitored message that is false and against consumers' interests. Specifically, in the context of the model, this implies that the CPA will withdraw any monitored false sign posted by firm $i$ that suggests to the consumer that further search is not worthwhile, when in fact the consumer would benefit from further search; when $p_{i}>p_{j}+c$. When compared to a more realistic decision rule that would withdraw a sign if $p_{i}>p_{j}$, this decision rule may look odd. However, under our simplifying assumption of uniform search costs, this decision rule provides more is preferred by consumers as it provides more meaningful information.

In Stage 4, consumers enter the market and automatically observe their local firms' price and message, $\left\{p_{i}, m_{i}\right\}$, before deciding whether to further search the non-local firm or not. A consumer's optimal search strategy will consist of two reservation prices, $r\left(m_{i}\right) \forall m_{i} \in\{$ Sign,NoSign $\}$, which describe the total expected cost of searching and buying from the non-local firm, conditional on the local firm's message $m_{i}$. A consumer will optimally buy at the local firm if $p_{i} \leq r\left(m_{i}\right)$ and choose to make a further search if not. Having further searched, the consumer will buy from the non-local firm $\mathrm{j}$, if $p_{j} \leq V$, exiting if not. Payoffs are then awarded.

In essence, firms pick prices in stage 1 and then participate in a cheap talk sender-receiver game with their local consumers, where messages may be mediated in some way by the CPA, in stages $2-4$.

In solving the game, we will only consider the set of symmetric Perfect Bayesian Nash Equilibria. Given the exogenous parameters of the model, 
$\{V, c, w\}$, an equilibrium will consist of the firm strategies $F\left(p_{i}\right)$ and $\left(m_{i} \mid P\right) \forall P$, and the consumer strategies $r\left(m_{i}\right) \forall m_{i} \in\{$ Sign, NoSign $\}$ such that all players' strategies are optimal with respect to other players' strategies, and any beliefs (over the non-local price) will be derived optimally through Bayes' rule. Crucially, as is standard within the search model literature, the equilibrium definition implies that a non-local firm $\mathrm{j}$ cannot induce a consumer at firm $i$ to search by the choice of its unknown price or expected price distribution alone.

\section{No Regulation Equilibrium}

To begin our analysis we start with the benchmark case where there is no regulation by the CPA by finding the game equilibrium when $w=0$.

Intuitively, as false messages have neither a cost nor a punishment, firms always prefer consumers to buy without further search. All messages are therefore incredible and the consumers rationally ignore them, making any comparison completely ineffective at deterring search and making the firms indifferent over the message space. As in the case where all price comparisons are banned, consumers are now left to make their costly search decisions using the ex ante expectation of non-local firms' prices alone; only searching if $p_{i}>r=E\left(p_{j}\right)+c$. Thus, as in the Diamond paradox (1971), a firm can always increase profits by increasing its price by an amount less than c at any pure strategy price equilibrium other than that at the monopoly price, $\mathrm{V}$. Consumers can do no better than to buy from their local firm and neither firm can profitably induce search by reducing its (unknown) price. This is formalised below.

The Benchmark Case: Given $\{V, c\}$ and either a level of consumer protection regulation of $w=0$ or a ban on price comparisons, there exist a unique equilibrium, where firms set $p_{i}=V$ and are indifferent over the message space $M$, and where consumers do not search, setting $r($ Sign $)=r($ NoSign $)=E\left(p_{j}\right)+c$. 
Proof: $\quad$ See Appendix

\section{Regulation Equilibria}

We now generalise the model to incorporate the effects of consumer protection by finding the game equilibria for $w \in[0,1]$. We start by finding the equilibrium messaging and search strategies for any given pricing distribution, and then further solve for the equilibrium stage 1 pricing strategies.

Firstly, when $p_{i} \leq \underline{p}+c$, the low price alone is sufficient for the consumer to make an optimal decision as the price is close enough to the lower bound, $\underline{p}$, to make search a dominated strategy. Consequently, the firm becomes indifferent over the message space.

In contrast, when $p_{i}>\underline{p}+c$, messages may in principle have value to the consumer as search may or may not be optimal. Firms will always have an incentive to try to persuade the consumer to buy by setting $m_{i}=$ Sign (apart from when $\mathrm{w}=1$ and $p_{i}>p_{j}+c$ where the firm will be indifferent as any message will be withdrawn with certainty). Hence, a consumer who observes $p_{i}>\underline{p}+c$ and $m_{i}=$ NoSign must rationally infer that $p_{i}>p_{j}+c$ as it must be the case that firm i created a false sales sign which was withdrawn (or the firm was indifferent, if $w=1)$. Using this inference, a consumer will optimally always search having observed no sales sign as the expected total cost of searching (the reservation price) will always be lower than the cost of buying without search as $r($ NoSign $)=E\left(p_{j} \mid p_{j}<p_{i}-c\right)+c<p_{i} \forall p_{i}$.

If instead $p_{i}>\underline{p}+c$ and $m_{i}=S i g n$, the consumer must rationally infer that either the sign is truthful implying that $p_{i} \leq p_{j}+c$, or that the sign is false but has not been monitored, implying that $p_{i}>p_{j}+c$. Using Bayes' rule, the consumer will search if $p_{i}>r(\operatorname{Sign})$, and buy without search if not, where $r(\operatorname{Sign})=$ 
$E\left(p_{j} \mid p_{j}<p_{i}-c\right)\left(\frac{F\left(p_{i}-c\right)(1-w)}{F\left(p_{i}-c\right)(1-w)+\left(1-F\left(p_{i}-c\right)\right)}\right)+E\left(p_{j} \mid p_{j} \geq p_{i}-c\right)\left(\frac{\left(1-F\left(p_{i}-c\right)\right)}{F\left(p_{i}-c\right)(1-w)+\left(1-F\left(p_{i}-c\right)\right)}\right)+c$

and where one can note that $r(\operatorname{Sign})=E\left(p_{j}\right)+c \quad$ when $\quad w=0$ and $r(\operatorname{Sign})=E\left(p_{j} \mid p_{j} \geq p_{i}-c\right)+c$ when $w=1$.

Given the search and messaging strategies found above, we now solve for the pricing equilibrium in stage 1 by finding the equilibrium values of $\underline{p}, \bar{p}$ and $F(p)$.

We note firstly that it must be true that $\bar{p} \leq \min \{r(\operatorname{Sign}), V\}$, as the consumer will always prefer to search or exit at prices beyond this upper bound. Consequently, having observed a sales sign a consumer will always buy without search. The expected demand function for firm $i$ can then be expressed as in (1) and understood as follows. If $p_{j}-c \leq p_{i} \leq p_{j}+c$ both firms can legitimately provide sales signs and trade with their local consumers. However, if prices are further apart, the higher priced firm will provide a false sign and either gain no demand if the sign is withdrawn with probability $\mathrm{w}$, prompting its local consumer to search elsewhere or the firm will successfully deter search and trade with its local consumer if the sign escapes monitoring, with probability $(1-\mathrm{w})$. The higher priced firm gains an expected demand of $(1-\mathrm{w})$, while the lower priced firm gains an expected demand of $(1+w)$.

$$
D\left(p_{i}, p_{j}, w, c\right)= \begin{cases}(1-w) & \text { if } p_{i}>p_{j}+c \\ 1 & \text { if } p_{j}-c \leq p_{i} \leq p_{j}+c \\ (1+w) & \text { if } p_{i}<p_{j}-c\end{cases}
$$

The discontinuities in (1) create equilibrium pricing strategies that are quite complex and vary in structure over three regions of regulation, $\mathrm{w}$. 
When regulation is 'low', $w \in[0, \underline{w}=c /(V-c)]$, the fraction of monitored messages is insufficient to break the Diamond monopoly pricing equilibrium. A price cut to $(\mathrm{V}-\mathrm{c})$ by firm $\mathrm{j}$ can only profitably break the equilibrium if the (now false) sign at firm $i$ is withdrawn to allow firm $j$ to attract the non-local consumer with a sufficiently high probability. Such a price cut will not be profitable when, $V \geq(V-c)(1+w)$ which is true when $w \leq \underline{w}=c /(V-c)$.

If instead, $w>\underline{w}$, the increased regulation of in-store messages improves the transmission of information concerning the price at firm $\mathrm{j}$ to consumers at firm $i$, in a way that can resolve the Diamond paradox. Higher regulation can allow false sales signs at firm i to be more frequently withdrawn, increasing the incentives of firm $\mathrm{j}$ to make a competitive price cut to attract firm i's consumers. However, note that markets with higher search costs require higher levels of regulation to do this, and even perfect regulation is insufficient to break the equilibrium if $c>(V / 2)$. When $w>\underline{w}$, there is no pure strategy pricing equilibrium as firms face incentives to both undercut each other and to increase prices by an amount less than c. Instead, the equilibrium pricing strategies consist of pricing distributions, $F(p) . F(p)$ will constitute an equilibrium distribution if $F^{\prime}(p) \geq 0 \quad \forall p$ and if the expected profits for all prices within the equilibrium price support generate a constant expected profit of $\theta$, while all other prices generate a profit strictly less than $\theta$.

Given that both firms price symmetrically with $F(p)$, we can express equilibrium profits by (2) where $(1-w F(p-c))$ expresses the probability that firm i trades with its local consumer - one minus the chance that firm j prices $c$ below firm $i$ and that firm i's false sign is withdrawn, and where $w(1-F(p+c))$ expresses the probability that firm i trades with its non-local consumers - the chance that firm $i$ undercuts firm $j$ by more than c multiplied by the probability that firm j's false sign is withdrawn. 


$$
\theta=p[(1-w F(p-c))+w(1-F(p+c))] \quad \forall p_{i} \in[\underline{p}, \bar{p}]
$$

In the appendix, we continue the equilibrium derivation by essentially using (2) to solve for the value of equilibrium profits, the pricing distribution and the equilibrium price support ${ }^{10}$. This creates two 'types' of mixed pricing strategies corresponding to when regulation is 'mid' $w \in(\underline{w}, \bar{w}]$, or 'high' $w \in(\bar{w}, 1]$, where $\bar{w}=((2 c(V-c)) /(V(V-2 c))$. In the mid regulation case the pricing distribution consists of a price support with a dominated middle region, and a mass point at prices equal to $\mathrm{V}$, while in the high regulation case the price support is continuous and bounded below V. This, and the entire game equilibrium are formally stated in the equilibrium proposition below.

Equilibrium Proposition: For a set of consumer parameters $\{V, c\}$ and $a$ level of consumer protection regulation of $w$, the game has a unique equilibrium, where

$$
\begin{aligned}
& r(\text { Sign })=E\left(p_{j} \mid m_{i}=\text { Sign }\right) \text { and } r(\text { NoSign })=E\left(p_{j} \mid p_{j}<p_{i}-c\right)+c \\
& \left.\left(m_{i} \mid P\right)=\text { Sign } \forall P \quad \text { (Although indifferent over M when } p_{i}<\underline{p}+c \text { or } w=1 \text { and } p_{i}>p_{j}+c\right)
\end{aligned}
$$$$
F(p)= \begin{cases}1 & \text { if } p \geq \bar{p} \\ 1-\frac{1}{w}\left(\left(\frac{\theta}{p-c}\right)-1\right) & \text { if } p \in[\underline{p}+c, \bar{p}) \\ 1-\frac{1}{w}\left(\frac{\theta}{p}-(1-w)\right) & \text { if } p \in[\bar{p}-c, \underline{p}+c) \\ 1-\frac{1}{w}\left(\frac{\theta-(p+c)(1-w)}{(p+c)}\right) & \text { if } p \in[\underline{p}, \bar{p}-c) \\ 0 & \text { if } p<\underline{p}\end{cases}
$$

10 The methods used in the appendix rely heavily on Shilony (1977) and indeed, our pricing equilibrium provides a generalisation of Shilony who characterised the special case where consumers have full information, which in our model corresponds to the case of $\mathrm{w}=1$. 
Where $\theta, \underline{p}$ and $\bar{p}$ are defined across three regions of $w . w$ is considered to be low when $w \in[0, \underline{w}]$, mid when $w \in(\underline{w}, \bar{w}]$ and high when $w \in(\bar{w}, 1]$, where $\underline{w}=(c /(V-c))$ and $\bar{w}=((2 c(V-c)) /(V(V-2 c))$. For each region,

Low w: $\quad \theta=V$

Mid $w: \quad \theta=(1 / 2)\left[c+(1-w) V+\sqrt{(c+(1-w) V)^{2}+4 w c V}\right]$

High w: $\quad \theta=(c / w)\left[1+\sqrt{1+w^{2}}\right]$

$$
\begin{aligned}
& \underline{p}=V, \quad \bar{p}=V \\
& \underline{p}=\theta-c, \bar{p}=V \\
& \underline{p}=\theta-c, \bar{p}=\theta+c
\end{aligned}
$$

To get a more intuitive grasp of the equilibrium and the effects of price comparisons, we now present the model's main results.

\section{Main Results}

Within the model, we are now interested in two comparative statics results. Firstly, we are interested in how the level of regulation affects, if at all, the ability of firms to deter search using false sales signs and secondly, how the level of regulation affects equilibrium consumer surplus.

We now show in Result 1, that moderate levels of consumer protection regulation can actually facilitate search deterrence.

Result 1: If we denote the expected ex ante probability that a consumer is deterred from otherwise optimal search due to the presence of a false sales sign as $\delta$, then $\delta$ is zero at $w \in[0, \underline{w}] \cup\{1\}$, but positive on $w \in(\underline{w}, 1)$. That is, regulation can facilitate search deterrence that would not otherwise exist, when $w \in(\underline{w}, 1)$.

\section{Proof: See Appendix}

Intuitively, when $\mathrm{w}=0$ in the benchmark case, messages had no credibility and consumers rationally ignored all sales signs. Alternatively, under perfect regulation, when $\mathrm{w}=1$, messages have credibility but all false signs are withdrawn by the authorities. It is only when regulation is of 'middle-order', $w \in(\underline{w}, 1)$, that search deterrence can exist as the moderate level of regulation 
provides a source of credibility for consumers but fails to fully eradicate false messages. This result provides an unusual characterisation of deception under the assumption of fully rational agents and formalises the arguments made by Nelson (1974), as referred to in the introduction, who stated that "Deception requires not only a misleading or untrue statement, but somebody ready to be misled by that statement" (p.749).

Result 2 now goes on to show that despite the facilitation of search deterrence, increased efforts by consumer protection authorities can never reduce consumer welfare.

Result 2: If we denote firms' equilibrium profits and expected consumer welfare as functions of the level of regulation $w$, as $\theta(w)$ and $C S(w)$ respectively, then $\theta^{\prime}(w) \leq 0 \forall w$ and $C S^{\prime}(w) \geq 0 \forall w$. That is, despite any effects on facilitating deception, firms cannot benefit and consumers cannot be harmed by any increase in regulation.

\section{Proof: See Appendix}

In essence, Result 2 can be understood best by considering the two effects that occur following an increase in the level of regulation.

The first effect documented by Result 1, which we label as the 'deterrence effect', shows that increases in regulation can facilitate search deterrence. This effect reduces consumer surplus by preventing consumers from optimally searching to benefit from buying at the lowest price on the market.

The second 'competition effect', increases consumer surplus and dominates the deterrence effect by reducing the equilibrium prices available on the market. This effect can be understood by interpreting the expected demand function given in (1). A 'winning' firm who has selected a price which is at least $\mathrm{c}$ below its competitor's price has profits that are increasing in the level of regulation, $\mathrm{w}$, while the losing firm's profits are decreasing in $\mathrm{w}$ and thus increases in regulation increase the intensity of competition. 
The implications of Result 2 for consumer protection policy are now considered in the next section, while the robustness and validity of using the model's results in wider contexts is discussed in section 6 .

\section{Policy Implications}

Under the assumptions of the model, Result 2 suggests that provided neither search costs nor the costs of monitoring are too large, CPAs can always improve consumer welfare and enhance competition by increasing the level of monitoring. This also indicates that the European Union was correct to remove some countries' bans on comparative advertising of this sort, as banning advertising in the model is consistent with the worst consumer welfare outcome.

A further implication of the model also suggests that it might be optimal to apply different levels of monitoring across markets that differ in the level of search costs. Markets with higher search costs require higher levels of monitoring to break the monopoly pricing equilibrium, while in markets with very high search costs, no amount of monitoring can ever improve consumer welfare. Such a strategy may be ultimately ineffective however, if, as a result, consumers become unsure about the level of regulation. For example if we consider an extreme case (outside the assumptions of game theory) where the level of regulation is not common knowledge and where consumers' believed regulation was full when in fact it was zero, then firms could sustain the Diamond equilibrium despite the efforts of the CPA. It is therefore advisable to ensure consumers are informed of the true level of regulation.

Although realistic in some cases, the form of regulation considered in the model may differ from that used by actual CPAs. For example, in the UK, CPAs often regulate the majority of messages after receiving a complaint from either a consumer or a rival firm, rather than using the random monitoring system considered here. Although, less costly to implement, a system based on consumer complaints would be ineffective in our model as no consumer 
who observes a false sales sign ever subsequently searches to learn it is false. However, a system based on firm complaints could be useful as a rival firm would always have the incentive to tell the authorities if the other firm created a false sign. Such a system could therefore allow the CPA to achieve perfect monitoring, although there would exist a dynamic incentive for firms to collude not to complain to achieve a more profitable, reduced level of w.

Finally, it is not clear if CPAs could benefit from administering fines in addition to withdrawing false price comparisons. In a previous version of this paper, Wilson (2004) showed some incomplete results suggesting that fines could act similarly to withdrawals but this remains an open policy question.

\section{Limitations and Robustness}

The model makes some simplifying assumptions which may call into question the external validity of the model and the applicability of the policy conclusions implications. In this section, we discuss the robustness of the model.

In solving the model we made use of the assumption that consumers could not return to the local store after searching elsewhere. This assumption is not crucial however, as the consumer, would never optimally return to the local firm, even if the consumer had such an option. The consumer only ever searches after observing no sales sign, which implies with certainty that $p_{i}>p_{j}+c$.

We also assume that firms are unable to create their own forms of credibility. Credibility could be gained through the usual dynamic signalling or reputation mechanisms. One could also interpret the use of price matching guarantees - where firms promise to refund any difference relative to a lower priced rival firm found by a consumer, as a possible credibility mechanism ${ }^{11}$.

11 This interpretation is gaining favour within the literature after Arbatskaya et al (2004) found that the more common interpretation of price matching guarantees as a facilitating 
Although these strategies are important, the qualitative effects of regulation are unlikely to change by incorporating them into the model.

One could expand the model by considering a wider message space rather than the simple binary message space. This could be handled within the model by reasonably assuming that different types of messages are open to different regulation levels. For example, a consumer may place more credibility on message stating the exact price of firm $\mathrm{j}$ in relation to the price of firm i, as it would be much easier for a CPA to monitor and evaluate such a message. Firms' strategic choice across different types of messages would clearly be an avenue for further research.

The model disallows firms from using out-of-store advertising to advertise their price to the non-local firm's consumer. Such advertising would vastly limit the potential for search deterrence by firms as consumers would now have two sources of information. However, it is not certain that such advertising would 'hit' the consumer with certainty and so the model as it stands could apply in such circumstances. Further, such advertising has a credibility problem of its own. The author is currently working on the implications of this in another model.

Finally, the model's timing can be criticised. It may be the case that the firm would like to change its price in response either to its rival's price or to being caught by the CPA and yet we assume that prices must remain fixed for the entire game. This is a genuine criticism of the model, but it is one also suffered by all models with mixed strategy equilibria.

\section{Conclusions}

Within a search-theoretic framework we have analysed how the monitoring of in-store sales signs by a consumer protection authority might influence 
consumers' search decisions and market competitiveness. Despite, facilitating an effect that deters optimal search, we have shown that monitoring is always preferred to a ban on comparisons and that increases in monitoring can always improve competition and consumer welfare (provided search and monitoring costs are not too large).

While this paper has begun to analyse the interface between consumer protection and competition with regard to one specific form of price advertising, the effect of other types of consumer protection policies and their effects in other areas of consumer protection remain largely under-developed. While the two policies are often well aligned, the interface becomes particularly interesting when the two policies are in conflict. For example, attempts to improve consumer information in the Danish concrete market also served to facilitate collusion (Albaek et al 1997). Further research in this regard is surely needed to inform future policy.

\section{References:}

Albaek S., Møllgaard H.P. and Overgaard P.G. (1997) “Government-Assisted Oligopoly Coordination? A Concrete Case" Journal of Industrial Economics vol.45 p.429-443

Anderson E.T. and Simester D.I. (1998) "The Role of Sale Signs" Marketing Science vol.17 p.139-155

Anderson E.T. and Simester D.I. (2001) "Are Sales Signs Less Effective When More Products Have Them?" Marketing Science vol.20 p.121-142

Arbatskaya M., Hviid M. and Shaffer G. (2004) "On the incidence and variety of low-price guarantees" Journal of Law and Economics vol.47(1) p.307-322

Barigozzi F. and Peitz M. (2004) "Comparative Advertising and Competition Policy" Working Paper

Beales H., Crasswell R. and Salop S.C. (1981) “The Efficient Regulation of Consumer Information" Journal of Law and Economics vol.24 p.491-539

Blair E.A. and Landon E.L. (1981) “The Effects of Reference Prices in Retail Advertisements" Journal of Marketing vol. 45 p.61-69 
Carlton D. and Perloff J. (1999) Modern Industrial Organisation, Third Edition Longman, New York

Compeau L.D. and Grewal D. (1998) "Comparative Price Advertising: An Integrative Review" Journal of Public Policy and Marketing vol.17 p.257-273

Diamond P.A. (1971) "A Model of Price Adjustment" Journal of Economic Theory vol.3 p.156-168

Ellison G. and Ellison S.F. (2004) "Search, Obfuscation and Price Elasticities on the Internet" NBER Working Paper 10570

Grewal D. and Compeau L.D. (1992) "Comparative Advertising - Informative or Deceptive" Journal of Public Policy and Marketing vol. 11 p.52-62

Inman J. J. et al (1990) "Promotion Signal: A Proxy For A Price Cut?" Journal of Consumer Research vol.17 p.74-81

Inman J.J. and McAlister L. (1993) "A Retailer Promotion Policy Model Considering Promotion Signal Sensitivity" Marketing Science vol.12 p.339-356

Ireland N. J. (2002) "Firm's Strategies for Reducing the Effectiveness of Consumer Price Search" Working Paper 627, University of Warwick

Moorthy S. and Winter R. A. (2002) "Price-Matching Guarantees" Review of Marketing Science (ROMS) Working Paper

Muris T.J. (2002) "The Interface of Competition and Consumer Protection" Remarks at the $29^{\text {th }}$ Annual Conference on International Antitrust Law and Policy

Nelson P. (1974) "Advertising as Information" Journal of Political Economy vol.82 p.729-754

OFT (2005) "Research into Misleading Price Comparisons" Prepared by the Nottingham Business School, June 2005

Putler D. (1992) "Incorporating Reference Price Effects Into a Theory of Consumer Choice" Marketing Science vol.11 p.287-309

Shilony Y. (1977) "Mixed Pricing in Oligopoly" Journal of Economic Theory vol.14 p.373-388

Spiegler R. (2005) “Competition Over Agents with Boundedly Rational Expectations "Working paper 
Stahl D. O. (1989) "Oligopolisitic Pricing with Sequential Consumer Search" American Economic Review" vol.79 p.700-712

Sylvan L. (2004) "Activating Competition: The Consumer - Competition Interface" Competition and Consumer Law Journal vol.12 p.191-206

Thaler R. (1985) "Mental Accounting and Consumer Choice" Marketing Science vol. 4 p.199-214

Urbany J.E. et al (1988) “The Effect of Plausible and Exaggerated Reference Prices on Consumer Perceptions and Price Search" Journal of Consumer Research vol. 15 p. $95-110$

Vickers J. (2003) "Economics for Consumer Policy" British Academy Keynes Lecture

Wilson C. M. (2004) "Price Deception, Market Power and Consumer Policy" CCP Working Paper 04-1

Wilson C. M. and Waddams Price C. (2005) "Irrationality in Consumers' Switching Decisions: When More Firms may Mean Less Benefit" CCP Working Paper 05-4

\section{Appendix:}

\section{Benchmark Case Proof:}

Due to the uniformity of firm preferences over consumers' actions all messages are incredible, and the unique messaging equilibrium involves consumers discarding messages and firms 'babbling 'over the message space. Thus, we can now ignore any strategic effects of messages and the conditions in stage 1 can be easily seen to replicate those needed to provide the Diamond paradox (1971).

\section{Pricing Equilibrium Proof:}

The derivation of the equilibrium pricing distribution is more complicated than in standard search models, largely due to the fact that we cannot directly identify equilibrium profits. As we shall later verify, equilibrium profits are the profits a firm can gain by pricing at the highest possible price while guaranteeing the trade of its local consumer, $\underline{p}+c$.

$$
\theta=\underline{p}+c
$$

However, as stated in (3) this expression is endogenous and so we must approach the derivation differently by firstly making assumption (A1) that states that it is never optimal for a firm to set a price that is $2 \mathrm{c}$ above the lower price boundary. We shall later show that (A1) will be true in equilibrium. 


$$
(\bar{p}-\underline{p}) \leq 2 c
$$

Using (A1) and (2) we can arrive at (4) by noting that for low prices $p \in[p, \bar{p}-c)$ a firm can assure its local custom for prices as $F(p-c)=0$. Further, by shifting the price support to the right by $c$, while subtracting $c$ from each price and rearranging, we can find an expression for the 'top' part of the distribution, which we will refer to as $\bar{F}(p)$ in (5).

$$
\begin{array}{ll}
\theta=p[1+w(1-F(p+c))] & \text { for } p \in[\underline{p}, \bar{p}-c) \\
\bar{F}(p)=1-(1 / w)[(\theta /(p-c))-1] & \text { for } p \in[\underline{p}+c, \bar{p})
\end{array}
$$

With a similar procedure, we can find the bottom part of the distribution $\underline{F}(p)$ by noting that at prices $p \in[\underline{p}+c, \bar{p})$ a firm can never attract a non-local consumer as $(1-F(p+c))=0$, which provides (6) and then (7).

$$
\begin{array}{ll}
\theta=p[(1-w F(p-c))] & \text { for } p \in[\underline{p}+c, \bar{p}) \\
\underline{F}(p)=1-(1 / w)[(\theta /(p+c))-(1-w)] & \text { for } p \in[\underline{p}, \bar{p}-c)
\end{array}
$$

Finally, if it exists, the region $p \in[\bar{p}-c, p+c)$ will be dominated by pricing at $p=\underline{p}+c$ as the firm cannot attract non-locals in this region, implying (8).

$$
\underline{F}(p)=1-(1 / w)[(\theta / \bar{p})-(1-w)] \quad \text { for } p \in[\bar{p}-c, \underline{p}+c)
$$

So now equations (5), (7) and (8) together constitute the full description of $\mathrm{F}(\mathrm{p})$ as described in the equilibrium proposition, but with $\theta, \underline{p}$ and $\bar{p}$ still to be derived for the two remaining cases of $w$, mid and high. We can now verify our initial statement in (3) that $\theta=\underline{p}+c$ by setting $\underline{F}(\underline{p})=0$ in (7).

In the first case, where $\mathrm{w}$ is high, $w \in(\bar{w}, 1]$ we shall later confirm that (A1) holds with equality; $(\bar{p}-p)=2 c$ such that $\bar{p}=\theta+c=p+2 c$. If we consider a price $p^{-} \in[\underline{p}+c, \bar{p})$ we know from (5) and (4) respectively, that

$$
\theta=p^{-}\left[\left(1-w F\left(p^{-}-c\right)\right)\right] \quad \text { and } \quad F(p)=(1 / w)[(\theta /(p-c))-1]
$$

which when combined, converges to (9) as $p^{-} \rightarrow \bar{p}=\theta+c$

$$
\theta=(\theta+c)[(\theta /(\theta-c))-w]
$$

which when solved implies

$$
\theta=(c / w)\left[1+\sqrt{1+w^{2}}\right]
$$


To now demonstrate that $(\bar{p}-p)=2 c$ is indeed optimal, we must show that any other upper bound, $\tilde{p} \neq \bar{p}=\underline{p}+2 c$ provides expected profits of less than $\theta$. It is easy to see that $\tilde{p}>\bar{p}$ generates lower profits as $\pi(p)<0$ for $p>\bar{p}$. To see that $\tilde{p}<\bar{p}$ is also sub-optimal consider the expected profits from pricing at $\tilde{p}, \theta=\tilde{p}[(1-w F(\tilde{p}-c))]$. However, as $\tilde{p}<\bar{p},(1-F(\tilde{p}-c))$ will now be in the flat region as $\tilde{p}-\underline{p}<2 c$ and so $\tilde{p}$ can always be profitably increased until reaching $\bar{p}$.

In the second mid $\mathrm{w}$ case, $\bar{p}$ becomes constrained by the upper limit $\mathrm{V}$. This occurs when $\bar{p}=c+(c / w)\left(1+\sqrt{\left.1+w^{2}\right)}=V\right.$ which when solved provides the boundary, $\bar{w}=(2 c(V-c)) /(V(V-2 c))$. In this mid case, $w \in(\underline{w}, \bar{w}],(\mathrm{A} 1)$ now holds with inequality as $\bar{p}$ is constrained. To find $\theta$ in this case, consider a price $\underline{p}^{-}$just below $\underline{p}$. From (3) we know that

$$
\theta \approx \underline{p}^{-}\left[1+w\left(1-F\left(\underline{p}^{-}+c\right)\right)\right]
$$

but again $\left(1-F\left(\underline{p}^{-}+c\right)\right)$ is in the flat region and so substituting for (7) and noting that as $\underline{p}^{-} \rightarrow \underline{p}=\theta-c$ and that $\bar{p}=V$ we arrive at (11), which when solved provides (12).

$$
\begin{aligned}
& \theta=(\theta-c)[1+((\theta / V)-(1-w))] \\
& \theta=(1 / 2)\left[c+(1-w) V+\sqrt{(c+(1-w) V)^{2}+4 w c V}\right]
\end{aligned}
$$

As w decreases, $\theta$ must be bounded by $\mathrm{V}$, which occurs at $\underline{w}=c /(V-c)$ which is the boundary for the low regulation, pure strategy region that we found previously.

\section{Result 1 Proof:}

The probability that a consumer at firm $\mathrm{i}$ is deterred from search due to a false sales sign can be expressed as $\delta=(1-w) \int_{\underline{p}+c}^{\bar{p}} \underline{F}(p-c) \bar{f}(p) d p \quad$ where $\bar{f}(p)=d \bar{F}(p) / d p$. This expression is composed of the probability that search would have been worthwhile, $\operatorname{Pr}\left(p_{j} \leq p_{i}-c\right)$ multiplied by the probability that the false sales sign was not withdrawn, $(1-\mathrm{w})$. One can note that $\delta=0$ for $w \in[0, \underline{w}] \cup\{1\}$. When $w \in[0, \underline{w}]$ the pure strategy pricing equilibrium exists, $\int_{p+c}^{\bar{p}} \underline{F}(p-c) d p=0$, and so all signs are ignored by the consumer, while when $\mathrm{w}=1$, all false signs are withdrawn with certainty and so deterrence is impossible. For $w \in(\underline{w}, \bar{w}), \delta>0$ and its value will depend upon whether $\mathrm{w}$ is in the mid or high region. In the high region, 
$\delta^{H}=(1-w) \int_{p+c=\theta}^{\bar{p}=\theta+c} F(p-c) \bar{f}(p) d p \quad$ which using the fact that $\int\left(1 /\left(p(p-c)^{2}\right) d p=\left(1 / c^{2}\right)(\ln p-\ln (p-c))-(1 /(c(p-c))) \quad\right.$ implies that $\delta^{H}=\frac{(1-w) \theta}{w^{2}}\left[\left(\theta / c^{2}\right) \ln \left(\frac{\theta^{2}}{\theta^{2}-c^{2}}\right)-(1 / \theta)\right]$, while in the case of mid regulation, $\delta^{M}=(1-w) \int_{\underline{p}+c=\theta}^{\bar{p}=V^{-}} \underline{F}(p-c) \bar{f}(p) d p+(1-w) \underline{F}(V-c) f(V)$ which when simplified, $\delta^{M}=\frac{(1-w) \theta}{w^{2}}\left[\frac{(V-\theta)}{(\theta-c)(V-c)}(1-(\theta / c))-\frac{\theta}{c^{2}} \ln \left(\frac{V(\theta-c)}{\theta(V-c)}\right)\right]+\frac{(1-w)}{w}\left[\left(1-\frac{\theta}{V}\right)\left(\frac{\theta}{(V-c)}-1\right)\right] \cdot \bullet$

\section{Result 2 Proof:}

To show $\theta^{\prime}(w) \leq 0 \quad \forall w$ it is sufficient to show that $\theta(w)$ is firstly, continuous in $\mathrm{w}$ and then to show that $\theta^{\prime}(w) \leq 0$ in each of the three regions of $\mathrm{w}$. Defining the profit expressions for each region of $\mathrm{w}$ by using a subscript $\mathrm{r}$, $\theta_{r} \forall r \in\{L, M, H\}$, one can show $\theta(w)$ is indeed continuous as $\theta_{L}(\underline{w})=\theta_{M}(\underline{w})$ and $\theta_{M}(\bar{w})=\theta_{H}(\bar{w}) \quad \forall \underline{w}, \bar{w} \in(0,1)$. It is then trivial to show that $\theta_{L}{ }^{\prime}(w)=0$ as $\theta_{L}=V$, and $\theta_{M}{ }^{\prime}(w)=(1 / 2) V\left[\frac{c-(1-w) V}{\left((c+(1-w) V)^{2}+4 c w V\right)^{1 / 2}}-1\right] \quad<0 \quad \forall w \in[0,1]$, while $\quad \theta_{H}{ }^{\prime}(w)=c\left[\left(1+w^{2}\right)^{-1 / 2}-w^{-2}\left(1+\left(1+w^{2}\right)^{1 / 2}\right]<0 \quad \forall w \in(0,1]\right.$.To show $C S^{\prime}(w) \geq 0 \forall w$, we express $C S(w)$ as the consumer's maximum willingness to pay minus the consumers' expected expenditure, minus the expected incurred search costs for any given level of regulation, w. Making use of the unit demand, zero marginal cost and symmetry assumptions a consumer's expenditure is equal to the expected profit of a single firm, $\theta(w)$. Thus, we once again using a subscript $\mathrm{r}$ to denote the region of $\mathrm{w}$ we can express $C S_{r}(w)=V-\theta_{r}(w)-c \operatorname{Pr}($ Search $) \quad \forall r \in\{L, M, H\}$. Again it is trivial to show that $C S_{L}{ }^{\prime}(w)=0$ as $C S_{L}(w)=0$ in this region as firms charge the monopoly prices and the consumer never searches. For the mid and high regions, when $w \in[\underline{w}, 1]$, we now show by contradiction that $C S^{\prime}(w)>0$. We know from above, that consumer expenditure is falling in $\mathrm{w}$ as $\theta^{\prime}(w)<0 \quad \forall w \in[\underline{w}, 1]$ and so if instead, consumer surplus was not increasing in $w$, then it must be the case that these reductions in expenditure must be offset or exceeded by associated increases in search costs. However, this can never be true as in equilibrium the consumer only ever searches when $p_{i}>p_{j}+c$, so that an increase in incurred search costs must be accompanied by a strictly larger reduction in expenditure. Consequently, $C S^{\prime}(w)>0$. 